\title{
Clinical outcomes and hospital length of stay in 2,756 elderly patients with hip fractures: a comparison of surgical and non-surgical management
}

Stephen Thong Soon $\underline{T a n}^{1}$, MBBs, Wei Ping Marcus $\underline{\operatorname{Tan}^{2}}$, Josephine Jaipaul${ }^{3}$, AdvDip, Siew Pang $\underline{\text { Chan }}{ }^{2}$, PhD, CMath, Sathappan S Sathappan ${ }^{1}$, FRCSEd

INTRODUCTION The purpose of this study was to compare the clinical outcomes of elderly hip fracture patients who received surgical treatment with those who received non-surgical treatment.

METHODS This retrospective study involved 2,756 elderly patients with hip fractures who were admitted over a six-year period. The patients' biodata, complications, ambulatory status at discharge and length of hospital stay were obtained from the institution's hip fracture registry.

RESULTS Among the 2,756 hip fracture patients, 2,029 (73.6\%) underwent surgical intervention, while 727 (26.4\%) opted for non-surgical intervention. The complication rate among the patients who underwent surgical intervention was $6.6 \%$, while that among the patients who underwent non-surgical intervention was $12.5 \%(p<0.01)$. The mean length of hospital stay for the surgical and non-surgical hip fracture patients was 15.7 days and 22.4 days, respectively $(p<0.01)$. CONCLUSION Surgical management of hip fractures among the elderly is associated with a lower complication rate, as well as a reduced length of hospital stay.

Keywords: hip fractures, hospital length of stay, non-surgical intervention, postoperative outcomes, surgical intervention

\section{INTRODUCTION}

Hip fractures are one of the most common types of fragility fractures encountered by orthopaedic surgeons. ${ }^{(1)}$ The worldwide incidence of hip fractures was 1.26 million in $1990,{ }^{(2)}$ and this number has been projected to reach 6.3 million by $2050 .^{(3)}$ In Singapore, the proportion of elderly patients in the general population is expected to increase over the next several decades. Geriatric patients are at high risk of hip fractures, and the management of hip fractures adds a significant economic burden to healthcare systems. ${ }^{(4,5)}$

There are two main types of hip fractures - femoral neck fractures (i.e. intracapsular) and intertrochanteric fractures (i.e. extracapsular). Management of hip fractures can be either surgical or non-surgical. Patients with hip fractures, regardless of whether they received surgical or non-surgical intervention, are predisposed to high complication rates (range 14\%-52\%). ${ }^{(6-8)}$ The one-year mortality rates range from $22 \%$ to $51 \%$ and are reported to be six times higher than in the general population. ${ }^{(9)}$ While surgical intervention is expected to be the ideal treatment option (since it permits faster functional recovery), there are limited studies comparing the outcomes of surgical and non-surgical treatments for hip fractures. ${ }^{(10-12)}$

Tan Tock Seng Hospital (TTSH), Singapore, is a major trauma centre in which hip fractures constitute about $8 \%$ of all orthopaedic emergency admissions. Clinical data on all patients who were admitted to TTSH with hip fractures has been entered into a hip fracture registry since the year 2000. The purpose of the present study was to review the epidemiological data of all patients with hip fractures and the clinical outcomes of surgical and non-surgical treatments for hip fractures.

\section{METHODS}

In TTSH, a hip fracture registry was developed for clinical audit, and has been in use since 2000. The clinical data of all patients aged $\geq 60$ years who were diagnosed with a hip fracture was entered into the registry. A hip fracture is defined as a femoral neck (i.e. intracapsular) fracture or an intertrochanteric (i.e. extracapsular) fracture. A dedicated research coordinator entered the relevant clinical data into an electronic database (Stata 9.0; StataCorp LP, College Station, TX, USA). Data was collected over a six-year period (2000-2005). The present study, a retrospective observational review of the hip fracture registry, was approved by the institutional review board.

During the six-year period, all the patients were under the care of senior orthopaedic surgeons, and geriatric physicians oversaw the clinical optimisation of the patients. They were advised to undergo surgical treatment and informed of the risks of both surgical and non-surgical management. No patient was excluded from surgical management on the basis of their age or American Society of Anesthesiologists (ASA) score.

Patients who consented to surgery underwent operative procedures that the senior orthopaedic surgeons deemed appropriate for their diagnosis. Orthopaedic registrars and consultants performed all the procedures. At the induction of anaesthesia, the patients were administered broad-spectrum antibiotics as a prophylaxis; this was continued postoperatively

${ }^{1}$ Department of Orthopaedic Surgery, Tan Tock Seng Hospital, ${ }^{2}$ Yong Loo Lin School of Medicine, National University of Singapore, ${ }^{3}$ Casemix Unit, Tan Tock Seng Hospital, Singapore Correspondence: Mr Marcus Wei Ping Tan, Medical Student, Yong Loo Lin School of Medicine, National University of Singapore, 1E Kent Ridge Road, NUHS Tower Block Level 11, Singapore 119228. a0090692@u.nus.edu 


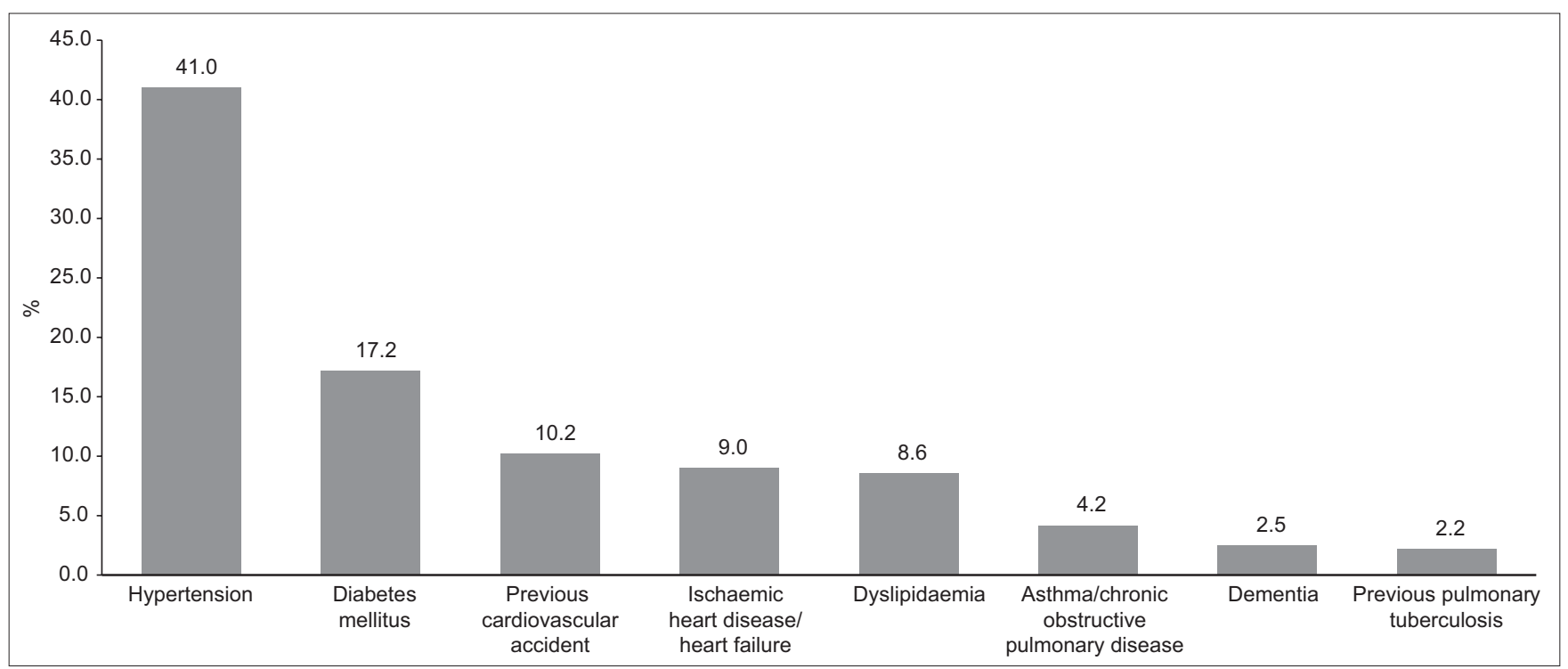

Fig. 1 Bar graph shows the comorbidity distribution of the patients with hip fractures $(n=2,756)$.

until the surgical drains were removed. Following surgical intervention, the patients were placed on a standardised postoperative clinical pathway for hip fractures. All the patients received antithrombotic stockings, but pharmacological agents for deep vein thrombosis (DVT) prophylaxis were selectively administered only to high-risk patients. When the patients attained satisfactory ambulatory status, they were discharged home or to an outpatient rehabilitation facility.

Patients who opted for non-surgical management were treated with skin leg traction until early fracture consolidation or clinical resolution of pain was noted. The patients were then started on appropriate assisted ambulation following physiotherapist review, and discharged to their own homes, rehabilitation hospitals or nursing homes once they had made stable early recovery. A multidisciplinary team, consisting of orthopaedic surgeons, geriatric physicians, physiotherapists, occupational therapists and orthopaedic specialist nurses, reviewed the patients in both the surgical and non-surgical treatment groups daily prior to their discharge.

Retrieval of clinical data was done by a single person (the author who was not involved in the clinical management of the hip fracture patients). The patients' biodata, operative interventions, complications following surgical/non-surgical treatment, ambulatory status at discharge and length of hospital stay (LOS) were reviewed. Chi-square test and Mann-Whitney $U$ test were used to compare the clinical characteristics and ambulatory status at discharge of both the surgical and non-surgical patients. Robust regression using iteratively reweighted least squares was applied to ascertain how the identified covariates were associated with LOS. All data was analysed with Stata 9.0. A p-value $<0.05$ was considered to be statistically significant.

\section{RESULTS}

A total of 2,756 patients aged $\geq 60$ years were admitted to TTSH with a diagnosis of hip fracture during the six-year period. The female-to-male ratio was $3: 1$, and the ethnic distribution of the patients was as follows: Chinese $89.2 \%$; Malay $5.3 \%$; Indian $4.0 \%$; Eurasian $0.5 \%$; and others $0.9 \%$. The types of hip fracture diagnosed were intertrochanteric fractures and femoral neck fractures. The mean age of the patients was 79.6 (range 50-108) years. The two most common comorbidities were hypertension and diabetes mellitus (Fig. 1).

Among the 2,756 patients, 2,029 (73.6\%) underwent surgical intervention and 727 (26.4\%) opted for non-surgical intervention (Table I \& Fig. 2). Slightly more than half of the patients who underwent surgical intervention were diagnosed with femoral neck fractures ( $n=1,081,53.3 \%$ ), while the remaining were diagnosed with intertrochanteric fractures ( $n=948,46.7 \%)$. The patients with intertrochanteric fractures underwent either dynamic hip screw fixation $(45.2 \%)$ or intramedullary nail stabilisation (i.e. Gamma nail or proximal femoral nailing) $(1.5 \%)$, while those with femoral neck fracture underwent cancellous screw fixation (1.4\%), unipolar hemiarthroplasty (i.e. Thompson's or Moore's prosthesis) (24.5\%) or bipolar hemiarthroplasty $(27.3 \%)$.

Complications following surgical treatment were recorded for 134 of the 2,029 patients (complication rate: 6.6\%). Most patients $(5.4 \%)$ presented with only one complication. The three most common complications were urinary tract infection $(1.9 \%)$, pressure sores $(1.0 \%)$ and wound infection $(0.7 \%)$. Among the 2,029 surgical patients, DVT was diagnosed in $11(0.5 \%)$; these patients were treated with appropriate oral anticoagulation therapy. The index mortality rate among the patients who underwent surgical treatment was $1.7 \%$ (i.e. 34 of the 2,029 patients died within 30 days following surgical intervention). Among the patients who opted for nonsurgical treatment, 91 had complications (complication rate: $12.5 \%)$. The three most common complications were pneumonia $(3.4 \%)$, acute coronary syndrome $(2.6 \%)$ and cerebrovascular accident $(2.1 \%)$. There were $54(7.4 \%)$ mortalities within the 30-day period following admission for hip fracture among this group of patients. 


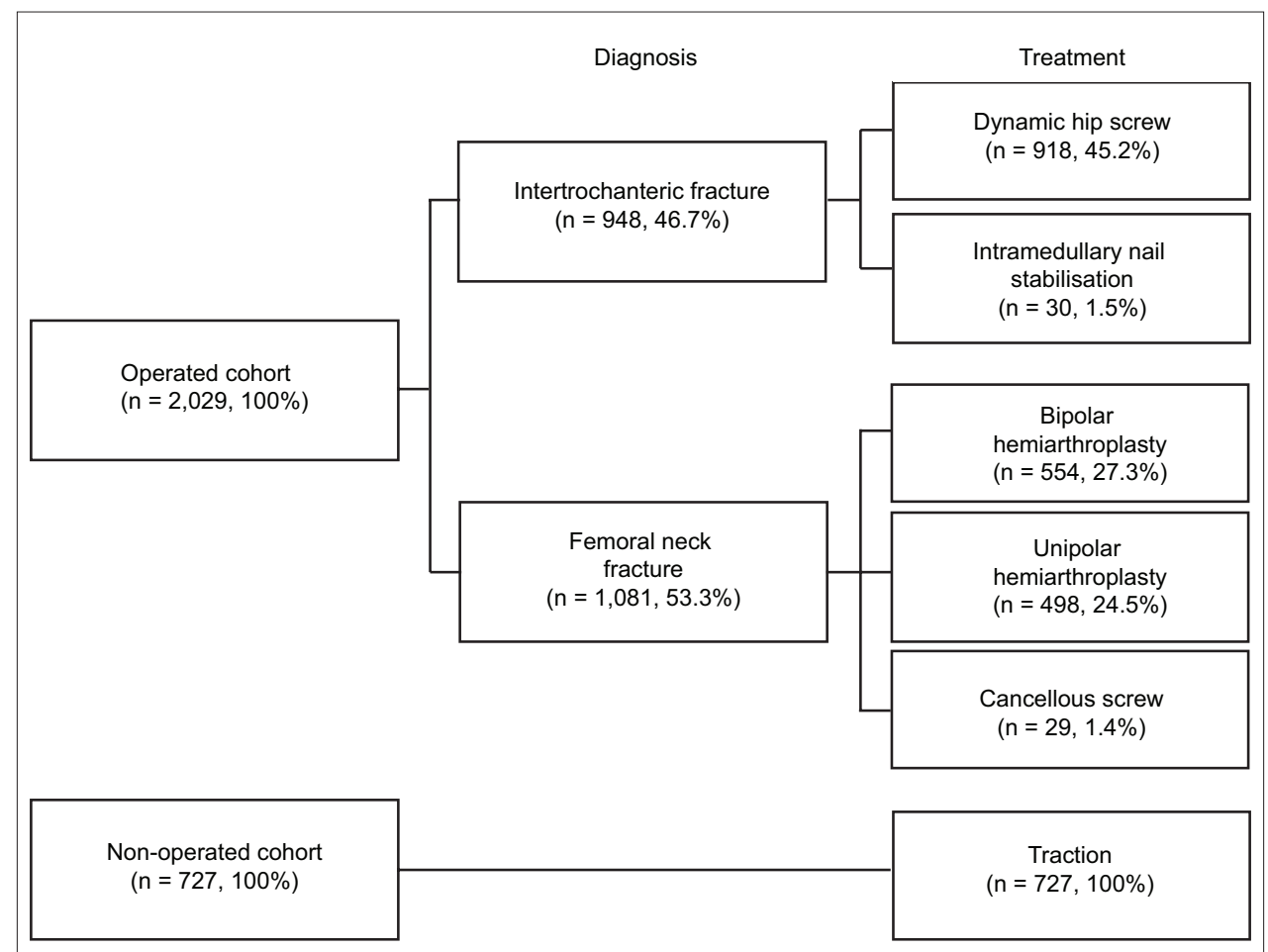

Fig. 2 Flow chart shows the diagnoses and types of treatment of patients with hip fractures $(n=2,756)$.

Table I. Clinical characteristics of patients $(n=2,756)$ according to type of treatment.

\begin{tabular}{lccc}
\hline Characteristic & \multicolumn{2}{c}{ No. (\%) } & p-value \\
\cline { 2 - 3 } & $\begin{array}{c}\text { Surgical } \\
\text { treatment } \\
(\mathbf{n}=\mathbf{2 , 0 2 9 )}\end{array}$ & $\begin{array}{c}\text { Non-surgical } \\
\text { treatment } \\
(\mathbf{n}=\mathbf{7 2 7})\end{array}$ & \\
\hline $\begin{array}{l}\text { Mean age (yr) } \\
\text { Gender }\end{array}$ & 78.8 & 81.9 & $<0.01$ \\
$\quad$ Male & $518(25.5)$ & $187(25.7)$ & 0.86 \\
$\begin{array}{l}\text { Female } \\
\text { No. of } \\
\text { comorbidities }\end{array}$ & $1,511(74.5)$ & $540(74.3)$ & \\
$\quad$ None & $860(42.4)$ & $276(38.0)$ & $<0.01$ \\
$\begin{array}{l}1 \\
\geq 2\end{array}$ & $469(23.1)$ & $149(20.5)$ & \\
$\begin{array}{l}\text { Diagnosis } \\
\text { Intertrochanteric } \\
\text { fracture }\end{array}$ & $948(46.7)$ & $340(46.8)$ & \\
$\begin{array}{l}\text { Femoral neck } \\
\text { fracture }\end{array}$ & $1,081(53.3)$ & $387(53.2)$ & \\
\hline
\end{tabular}

The breakdown of complications among the patients who underwent surgical and non-surgical treatments is shown in Figs. 3 and 4, respectively. On statistical analysis, the complication rate among the patients who underwent surgical treatment was found to be significantly lower than that among those who underwent non-surgical treatment $(p<0.01$; odds ratio $0.49,95 \%$ confidence interval $0.37-0.65$ ). In other words, a patient who underwent non-surgical treatment had almost twice the odds of developing a complication as compared to a patient who underwent surgical treatment.
The median (range) and mean LOS of the patients who underwent surgical treatment were 14 (range 2-93) days and 15.7 days, respectively, while those of the patients who underwent non-surgical treatment was 18 (range 0-163) days and 22.4 days, respectively. By comparison, the mean LOS of the patients who underwent surgical treatment was significantly lower than that of the patients who underwent non-surgical treatment $(p<0.01)$. Among the patients who received surgical treatment, more than half $(55.0 \%)$ attained independent ambulatory status (with or without walking aids) and most were discharged home (49.8\%) or to a rehabilitation centre $(32.0 \%)$. Among the non-surgical patients, 397 (54.6\%) were discharged home, while 91 (12.5\%) were discharged to a rehabilitation hospital to continue to gain assistance in mastering daily living skills for an extended period of time. The disposition outcome data of the two groups of patients is shown in Table II.

\section{DISCUSSION}

Patients with hip fractures have a considerable risk of various medical and surgical complications, prolonged LOS and mortality. ${ }^{(7,8,13)}$ Surgical fixation of these fractures facilitates favourable clinical recovery, and the various determinants of clinical outcome have been extensively reviewed.(14-16) Many authors have noted that undue delay in surgical treatment increases morbidity and mortality following hip fractures. ${ }^{(17,18)}$ Surgical intervention facilitates early mobilisation and early discharge of patients, thereby lowering LOS. Extended LOS is unfavourable, as it increases the risk of acquiring nosocomial infections. ${ }^{(19)}$ Furthermore, early mobilisation decreases the risk of the typical complications associated with recumbency (i.e. pneumonia, decubitus ulcers and DVT). 


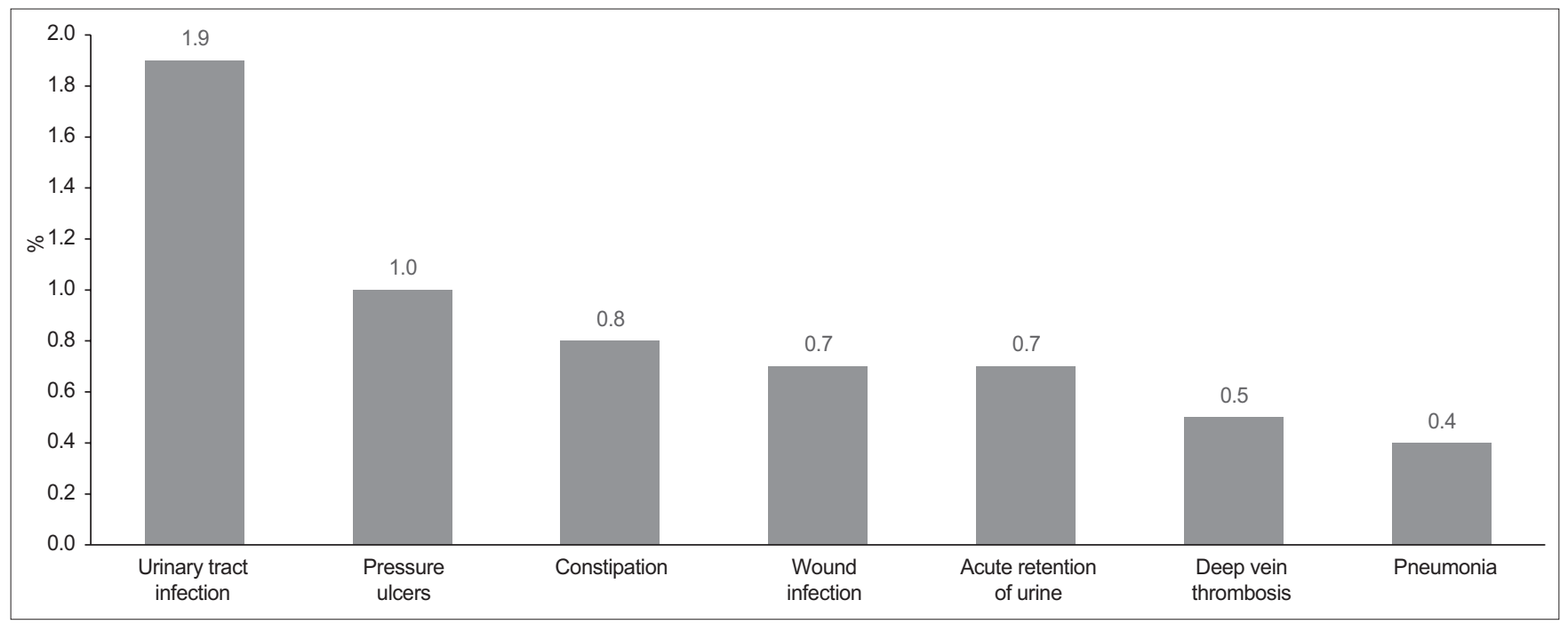

Fig. 3 Bar graph shows the complications among the patients who underwent surgical treatment $(n=2,029)$.

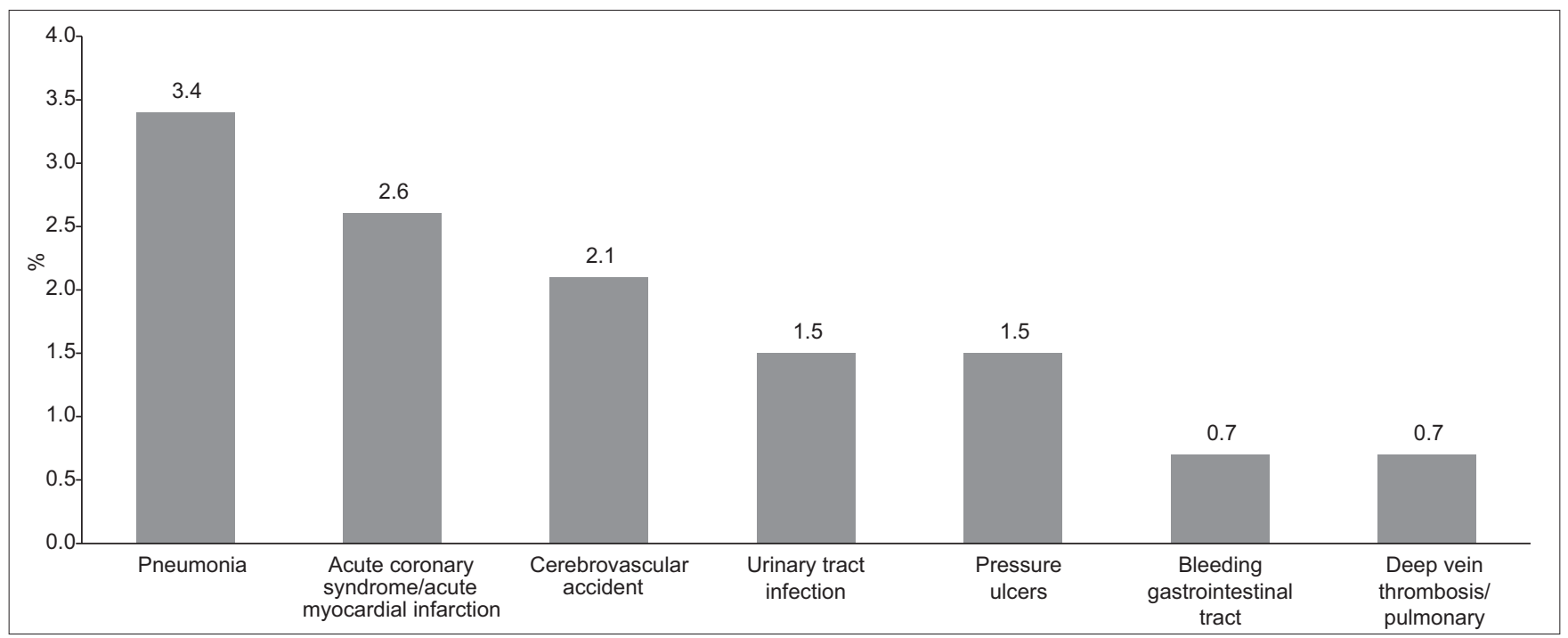

Fig. 4 Bar graph shows complications among the patients who underwent non-surgical treatment $(n=727)$.

Table II. Clinical outcomes of patients $(n=2,756)$ according to type of treatment.

\begin{tabular}{|c|c|c|c|}
\hline \multirow[t]{2}{*}{ Outcome } & \multicolumn{2}{|c|}{ No. (\%) } & \multirow[t]{2}{*}{$p$-value } \\
\hline & $\begin{array}{c}\text { Surgical } \\
\text { treatment } \\
(n=2,029)\end{array}$ & $\begin{array}{c}\text { Non-surgical } \\
\text { treatment } \\
(n=727)\end{array}$ & \\
\hline $\begin{array}{l}\text { No. of complications } \\
\text { (complication rate) }\end{array}$ & $134(6.6)$ & $91(12.5)$ & $<0.01$ \\
\hline Mean LOS (day) & 15.7 & 22.4 & $<0.01$ \\
\hline $\begin{array}{l}\text { Index mortality rate } \\
\text { (30-day mortality rate) }\end{array}$ & $34(1.7)$ & $54(7.4)$ & $<0.01$ \\
\hline Disposition & & & $<0.01$ \\
\hline Home & $1,011(49.8)$ & $397(54.6)$ & \\
\hline Rehabilitation centre & $649(32.0)$ & $91(12.5)$ & \\
\hline Nursing home & 369 (18.2) & 239 (32.9) & \\
\hline
\end{tabular}

LOS: length of hospital stay

In the present study, the complication rate was significantly lower among hip fracture patients who underwent surgical treatment than those who underwent non-surgical treatment.
Although some studies have suggested that there is an increased risk of complications among older patients who undergo surgery for hip fractures, other studies have shown no such association. ${ }^{(8,15)}$ The patients in this study were not denied surgical treatment on the basis of age or ASA scores; this might account for the fact that the index mortality rate in the present study $(1.7 \%)$ was comparable to the rates reported in other studies. ${ }^{(5,7)}$ Although the overall complication rate was lower for the patients who underwent surgical treatment, there is a finite risk of mortality associated with undergoing surgery for hip fractures. Since hip fractures almost exclusively affect older patients (who have lower physiological reserves), there is a definite operative risk secondary to anaesthesia and blood loss. Also, despite the immediate benefits of surgical intervention, complications secondary to suboptimal fracture fixation have been reported, at 15\%-55\%. ${ }^{(16)}$

Non-surgical treatment conventionally involves the use of skeletal traction for an extended period of several weeks. ${ }^{(11,20)}$ This, however, increases the risk of pin-site infections and decubitus ulcers. In TTSH, most of the patients who opted for non-surgical 
treatment were given skin leg traction for 4-8 weeks until clinical resolution of pain; thereafter, the patients were started on early rehabilitation exercises. It has been reported that an extended period of bed rest with traction can increase the risk of morbidity and mortality among patients with hip fractures who opt for nonsurgical treatment. ${ }^{(21)}$

The literature comparing surgical and non-surgical treatment of hip fractures is sparse, and there is a lack of objective comparisons. ${ }^{(10,11,13)}$ Ethical considerations hinder the possibility of randomised studies to evaluate the immediate postoperative outcomes of these two treatment modalities. Although the differences between the two treatment modalities may seem obvious, the present study provided clinical data on the different postoperative outcomes of surgical and non-surgical treatments, which was based on a sizable study population. This data can be used by physicians to advise patients about their treatment options, as part of the informed consent process.

The present study was not without limitations. As this was a retrospective study, randomisation of treatment received by the patients could not be done. While significant differences in age and comorbidities between the two treatment groups should ideally be matched, the patients in both treatment groups were similar in their age and comorbidity distribution. Hence, matching techniques (such as propensity score matching) were not carried out, as the disadvantages associated with the use of such techniques (including introducing bias and a loss of power) ${ }^{(22)}$ were anticipated to outweigh the minor confounding effect of age and comorbidity. Other than that, since the data used in this study was retrieved from the hip fracture registry of our hospital, which only tracked patients during their inpatient stay and for any readmissions within 30 days, no long-term data was available on the patients who underwent surgical and nonsurgical treatments.

To conclude, surgical management of hip fractures has a more favourable postoperative outcome (i.e. decreased complication rate) and is also associated with a shorter LOS than non-surgical management of hip fractures.

\section{REFERENCES}

1. Gehlbach SH, Avrunin JS, Puleo E. Trends in hospital care for hip fractures. Osteoporos Int 2007; 18:585-91.

2. Gullberg B, Johnell O, Kanis JA. World-wide projections for hip fracture. Osteoporos Int 1997; 7:407-13.

3. Cooper C, Campion G, Melton LJ 3rd. Hip fractures in the elderly: a world-wide projection. Osteoporos Int 1992; 2:285-9.

4. Cotter PE, Timmons S, O'Connor M, Twomey C, O'Mahony D. The financial implications of falls in older people for an acute hospital. Ir J Med Sci 2006; 175:11-3.

5. Wong MK, Arjandas, Ching LK, Lim SL, Lo NN. Osteoporotic hip fractures in Singapore--costs and patient's outcome. Ann Acad Med Singapore 2002; 31:3-7.

6. Clayer MT, Bauze RJ. Morbidity and mortality following fractures of the femoral neck and trochanteric region: analysis of risk factors. J Trauma 1989; 29:1673-8.

7. Nather A, Seow CS, lau P, Chan A. Morbidity and mortality for elderly patients with fractured neck of femur treated by hemiarthroplasty. Injury 1995; 26:18790.

8. Ooi LH, Wong TH, Toh CL, Wong HP. Hip Fractures in nonagenarians--a study on operative and non-operative management. Injury 2005; 36:142-7.

9. Keene GS, Parker MJ, Pryor GA. Mortality and morbidity after hip fractures. BMJ 1993; 307:1248-50.

10. Cserháti P, Kazár G, Manninger J, Fekete K, Frenyó S. Non-operative or operative treatment for undisplaced femoral neck fractures: a comparative study of 122 non-operative and 125 operatively treated cases. Injury 1996; 27:583-8.

11. Parker MJ, Handoll HH, Bhargara A. Conservative versus operative treatment for hip fractures. Cochrane Database Syst Rev 2000; CD000337.

12. Villar RN, Allen SM, Barnes SJ. Hip fractures in healthy patients: operative delay versus prognosis. Br Med J (Clin Res Ed) 1986; 293:1203-4.

13. Hornby R, Evans JG, Vardon V. Operative or conservative treatment for trochanteric fractures of the femur. A randomised epidemiological trial in elderly patients. J Bone Joint Surg Br 1989; 71:619-23.

14. Endo Y, Aharonoff GB, Zuckerman JD, Egol KA, Koval KJ. Gender differences in patients with hip fracture: a greater risk of morbidity and mortality in men. J Orthop Trauma 2005; 19:29-35.

15. Merchant RA, Lui KL, Ismail NH, Wong HP, Sitoh YY. The relationship between postoperative complications and outcomes after hip fracture surgery. Ann Acad Med Singapore 2005; 34:163-8.

16. Foss NB, Palm H, Krasheninnikoff $M$, Kehlet $H$, Gebuhr P. Impact of surgical complications on length of stay after hip fracture surgery. Injury 2007; 38:780-4.

17. Bredahl C, Nyholm B, Hindsholm KB, Mortensen JB, Olesen AS. Mortality after hip fracture: results of operation within $12 \mathrm{~h}$ of admission. Injury 1992; 23:83-6.

18. Casaletto JA, Gatt R. Post-operative mortality related to waiting time for hip fracture surgery. Injury 2004; 35:114-20.

19. Umarji SI, Lankester BJ, Prothero D, Bannister GC. Recovery after hip fracture. Injury 2006; 37:712-7.

20. Bong SC, Lau HK, Leong JC, Fang D, Lau MT. The treatment of unstable intertrochanteric fractures of the hip: a prospective trial of 150 cases. Injury $1981 ; 13: 139-46$.

21. Jain R, Basinski A, Kreder HJ. Nonoperative treatment of hip fractures. Int Orthop $2003 ; 27: 11-7$.

22. Stone CA, Tang Y. Comparing propensity score methods in balancing covariates and recovering impact in small sample educational program evaluations. Prac Assess Res Eval 2013; 18:1-12. 